\title{
RBEP
}

\section{O Programa de Educação Tutorial: conexões de saberes no diálogo com as trajetórias de estudantes de origem popular}

Valdete Côco

\section{Resumo}

Na observação de que, no contexto das problemáticas sociais, a educação vem se afirmando como um direito, fortalecendo a luta pelo aumento da oferta e por programas de apoio ao acesso e à permanência, aborda-se neste trabalho a escolarização de jovens universitários de origem popular em associação com a proposição de projetos de apoio a esses sujeitos. Na articulação com a pesquisa Trajetórias de Estudantes e com o desenvolvimento do Programa de Educação Tutorial: Conexões de Saberes, focalizam-se as trajetórias de um grupo de estudantes que culminaram com o ingresso na universidade (em cursos de formação de professores) e as experiências marcantes no início da vida universitária com a inserção no Programa. Nesse propósito, resgata os percursos situando a escolarização no conjunto das experiências vividas, explora os desafios apontados com o ingresso na universidade e considera as perspectivas de continuidade da trajetória em interface com o investimento institucional na formação dos estudantes.

Palavras-chave: democratização do acesso ao ensino; Programa de Educação Tutorial; conexões de saberes; docência. 


\section{Abstract \\ The Tutorial Education Program: the relation between the Knowledge Connections Program and the trajectories of students from underprivileged backgrounds}

By observing that, in the context of the social issues, education has been reaffirming itself as a right, strengthening the fight for the increase in its offering and for programs that give support to the access and permanence of students in the education system. In this study the focus is on the education process of the minority students, in this case young undergraduate students from underprivileged backgrounds and its relation to the projects designed to support them. In conjunction with the research "Students' Trajectories" and with the development of Tutorial Education Program (TEP): Knowledge Connections, we focus on the trajectories of a group of students who entered the university (in courses forming teachers) and their remarkable experiences at the beginning of their college lives with the inclusion in the Program. Thus, this study highlights the students' trajectories analyzing the schooling process under the perspective of their life experiences, explores the challenges faced with the students' entry in the university and takes into consideration the perspectives of continuity in their trajectories in association with the institutional investments in forming students.

Keywords: democratization of education access; the Tutorial Education Program; knowledge connections; teaching.

\section{Introdução}

Vivemos um movimento de luta pela afirmação da cidadania - bem como dos elementos associados a esse campo semântico, tais como cidadão, direitos, democracia, princípios igualitários, etc. -, numa tensão com o estabelecimento de formas cada vez mais sofisticadas de desigualdades sociais (Castel, 1997). O legado desse jogo resulta na possibilidade de invenção/criação de novos direitos, delineando uma lógica do direito a ter direitos (Dagnino, 1994, p. 107; Bobbio, 2004, p. 25), que sustenta os esforços na luta por conquistas sociais. Nesse terreno, a educação vem se afirmando como um direito, mobilizando o aumento da oferta, numa vinculação com a ampliação dos anos de escolarização e com a discussão das formas de acolhimento dos distintos segmentos sociais no desenvolvimento das políticas educacionais.

Na problematização das iniciativas associadas à democratização do acesso ao ensino, situamos este trabalho no diálogo com o conjunto de 
iniciativas vinculadas às políticas de ações afirmativas tomadas como ações de incentivo e suporte às pessoas e/ou grupos a que se destinam. Nessa perspectiva, abordamos as trajetórias de escolarização de jovens universitários de origem popular em articulação com a proposição de projetos de apoio a esses sujeitos. Tomamos o contexto de associação entre o Programa Conexões de Saberes, vinculado ao apoio a estudantes de origem popular, e o Programa de Educação Tutorial (PET), criado para apoiar atividades acadêmicas que integram ensino, pesquisa e extensão, a partir da configuração de um dos grupos de trabalho.

Assim, considerando o desenvolvimento do PET: Conexões de Saberes, especificamente o grupo relativo ao Projeto Educação e em articulação com a pesquisa Trajetórias de Estudantes, partimos da concepção de que "o real é processual" para evidenciar a historicidade das ações (Konder, 2002, p. 187) e potencializar a ação dos sujeitos na história (Freire, 1998, p. 47). Com esses aportes, observamos as marcas nas trajetórias dos sujeitos inseridas no jogo interativo das mediações sociais, que vão negociando os modos de configuração dos percursos na dinâmica complexa e conflituosa da vida cotidiana. Com isso, aventamos uma diversidade de possibilidades de itinerários que não se descolam das tensões negociativas presentes na dialogia constitutiva do conjunto das lutas por conquistas sociais (Bakhtin, 1992, 1993).

Nesse jogo, observamos os programas voltados ao apoio a jovens universitários de origem popular inseridos num repertório de discussão sobre a temática da juventude, em especial no recorte sobre as formas de interlocução do jovem com o poder público, no movimento de produção de políticas públicas endereçadas a esse segmento. Cabe observar que, no projeto, a ideia de jovens universitários se refere aos iniciantes na universidade, permitindo o ingresso de alunos até o terceiro período dos cursos. Em sua maioria, eles também são jovens no aspecto geracional, mas não necessariamente. De todo modo, marcando a complexidade da temática (Pais, 1990; Rua, 1998; Freitas, Papa, 2003; Sposito, 2000a, 2000b, 2003) - que envolve a consideração sobre as fases da vida e a produção das desigualdades de classes sociais, gênero, etnia e outras -, dialogamos com a ideia de juventude como uma construção histórico-social. Essa ideia implica a distinção entre condição e situação juvenil (Abad, 2003) na observação da experiência de ser jovem no cenário brasileiro, em especial no pertencimento aos segmentos populares.

É preciso um olhar aproximado, um exercício de sensibilidade, para capturar as nuanças, as belezas e a complexidade que vive a juventude. De longe, podemos incorrer no erro de considerar uma massa de projetos de gente com dilemas muito parecidos. É preciso sair da superfície para olhar os retratos da vida que chegam à universidade. Com essa perspectiva, inserimos nossa aproximação ao grupo integrante do Projeto Educação no movimento interativo entre os estudantes e a instituição, um movimento situado num contexto particular, mas que não pode ser dissociado das pautas em discussão na vida social. Na interação mais direta com a instituição, consideramos que os estudantes tanto usufruem da vida 
universitária, agregando novos saberes, quanto colaboram ativamente na (re)produção desse contexto, trazendo suas experiências e demandas para as negociações. Esse encontro, marcado por tensões, também interage com um contexto mais ampliado de proposição das políticas públicas, em especial da política educacional.

No campo educativo, o Projeto Educação mobiliza endereçamentos mais diretos às políticas de apoio a estudantes de origem popular, dada a configuração do grupo. Também dialoga com as políticas vinculadas à formação de professores, visto que reúne estudantes de cursos que têm a docência como horizonte de atuação profissional (Pedagogia, Artes e Educação Física) e, ainda, estão inscritos num projeto cujo propósito extensionista se concretiza no cenário de uma instituição educativa. Em síntese, pautamos o trabalho na ideia da educação como um direito que, no seu percurso, pode ser ressignificado pelos diferentes atores na dinâmica social, ecoando nas formas como negociamos os incentivos aos jovens universitários de origem popular e, sobretudo, nos distintos percursos formativos empreendidos.

Desse modo, focalizamos as trajetórias do grupo de estudantes que culminaram no ingresso na Universidade e as experiências marcantes nos momentos iniciais da vida universitária com a inserção no Programa. Estabelecemos um percurso metodológico vinculado à realização de estudo qualitativo exploratório (Bogdan, Biklen, 1994), inserido na concepção de homem como produtor de textos (Bakhtin, 1992, p. 334). Essa concepção nos remete às relações de conhecimento produzidas em interface com a observação dos lugares sociais diferenciados e hierarquicamente organizados ocupados pelos interlocutores, que mobilizam a emergência de formas variadas de apreensão e articulação, colocando em circulação, explicitamente ou não, uma multiplicidade de sentidos que imprimem marcas diferenciadas nas relações, visando o controle dos sentidos em circulação (Fontana, 1993, p. 127). Assim, o dizer dos estudantes é pesquisado no reconhecimento do caráter contextual das enunciações e da complexidade da construção dos sentidos para as pautas em questão (Bakhtin, 1998, p. 141; 1992, p. 386). Com isso, realizamos um estudo que se volta para uma dimensão mais restrita da realidade social - as trajetórias do grupo de estudantes - ao mesmo tempo em que procura manter relações entre os planos macro e microssocial na discussão das conquistas sociais.

Na precariedade das pequenas conquistas no campo das políticas educacionais, buscamos os estudantes como sujeitos comuns e, simultaneamente, institucionais (alunos universitários) em interação com outros sujeitos e discursos, num processo contínuo de atribuição de sentidos. Para o movimento investigativo em direção às trajetórias que culminaram no ingresso na universidade, desenvolvemos procedimentos para a coleta de dados que abarcaram a produção de memoriais pelos universitários no momento do ingresso no Programa, a apresentação/discussão em grupo focal desses materiais e a produção de síntese coletiva pelos estudantes, reunindo as trajetórias compartilhadas no grupo. Na abordagem das 
experiências marcantes no início da vida universitária com a participação em atividades de ensino, pesquisa e extensão, mobilizadas em parceria com a inserção no Programa, trabalhamos com a produção de diário de campo com registros individuais e a discussão em grupo focal de experiências destacadas pelos estudantes. No conjunto da pesquisa, são agregadas outras produções dos estudantes, desenvolvidas conforme o andamento do projeto. Cabe observar que os materiais são produzidos integrados ao desenvolvimento das ações (oficinas de formação, desenvolvimento de atividades diversas, organização de reuniões, participação e apresentação em eventos, etc.) e, no conjunto, são tomados como fonte para a pesquisa. "Sem dúvida, a reunião do grupo focal [...] nos marcou muito. Compartilhamos nossos memoriais e a emoção foi um sentimento bem presente" (Alves et al., 2011, p. 3).

Nesses procedimentos, cultivamos um cuidado no olhar, considerando a advertência proposta por Bakhtin (1992, p. 26-27):

Quantos véus, que escondem a face do ser mais próximo, que parecia perfeitamente familiar, não precisamos [...] levantar, véus depositados nele pelas casualidades de nossas reações, de nosso relacionamento com ele e pelas situações da vida, para ver-lhe o rosto em sua verdade e seu todo.

A partir da advertência de considerar o comprometimento do olhar em função do lugar que ocupamos, pautamos nosso exercício de exotopia (Bakhtin, Volochínov, 1997) na busca do descentramento de uma visão acabada. No investimento em uma "escuta sensível" (Barbier, 1996), procuramos a riqueza das nuanças para escapar da armadilha da cultura da pobreza, entendida "como uma falta natural e totalizante dos sujeitos que são pobres", dirigindo o olhar para uma cultura da sobrevivência, perseguindo as ideias de ação, intervenção, criatividade, coragem, cooperação e solidariedade, no enfrentamento de situações impulsionadoras da existência humana (Souza, 2003, p. 253) para produzir a continuidade da vida.

Assim, trabalhamos com dados situados num contexto de produção que movimenta e dinamiza múltiplas vozes: as pautas em disputa no contexto social, as premissas apresentadas nas políticas de ações afirmativas, a institucionalidade da universidade, os requisitos do projeto em desenvolvimento, os desejos e necessidades dos estudantes, a pesquisa em curso... O reconhecimento de que as relações dialógicas permeiam todos os discursos, relações e manifestações da vida humana (Morson, Emerson, 2008, p. 67) instiga o cuidado com as implicações dos sujeitos com a pesquisa, visto que ela também integra os inúmeros espaços de endereçamento no diálogo contínuo da existência. Nos desafios da pesquisa, buscamos abordar a triangulação dos dados, considerando diferentes entradas analíticas (textos individuais, sínteses coletivas, discussão coletiva, etc.) e o próprio diálogo como potencial de distintas formas de compreensão. Compreensões que se transformam, alteram, renovam e se dirigem a diferentes interlocutores (Velho, 2004, p. 121-132). Com isso, no quadro teórico-metodológico proposto, destacamos que "[...] não se 
podem contemplar, analisar e definir as consciências alheias como objetos, como coisas: comunicar-se com elas só é possível dialogicamente. Pensar nelas implica conversar com elas [...]" (Bakhtin, 2005, p. 68).

Nesse fazer com, trazemos a experiência de quem vivencia a formação de estudantes por dentro (como professora universitária e tutora do grupo), procurando um ponto de observação privilegiado para discussão das trajetórias dos estudantes. Buscamos oportunidades de rever e enriquecer os resultados da pesquisa a partir do confronto intelectual e emocional das diferentes versões e interpretações postas para os fatos e situações relacionadas à investigação. Essa dinâmica é favorecida pelo movimento dos estudantes, sempre dispostos a discutir coletivamente os dados que emergem nos instrumentos e mobilizados para sistematizar textos que contribuem para dinamizar a teia dialógica sobre as ações de apoio aos jovens universitários de origem popular. Esses momentos de revisão do olhar percorrem diferenciados sentimentos, uma vez que "[...] o olho que perscruta e quer saber objetivamente das coisas pode ser também o olho que ri ou chora, ama ou detesta, admira ou despreza. Quem diz olhar diz, implicitamente, tanto inteligência quanto sentimento" (Bosi, 1999, p. 41).

No propósito de ampliação da interlocução, resgatamos os percursos situando a escolarização no conjunto das experiências vividas, exploramos os desafios apontados com o ingresso na universidade e consideramos as perspectivas de continuidade da trajetória em interface com o investimento institucional na formação dos estudantes. Tecemos reflexões a partir dos materiais coletados (memoriais - M e diários de campo - DC) e das sínteses produzidas pelo grupo (Soares et al., 2011; Alves et al., 2011), indicando a produção de um texto a muitas mãos.

\section{Trajetórias rumo à universidade}

No trabalho com memoriais e com a apresentação e discussão coletiva dessas produções, destacamos, a partir de uma síntese dos princípios bakhtinianos propostos por Morson e Emerson (2008), o reconhecimento de que, ao analisarmos as trajetórias dos estudantes, estamos compondo uma linha de pensamento. Produzimos uma completude, montamos um todo arquitetônico de comunicação com os interlocutores, uma espécie de unidade que as trajetórias podem não possuir. No encontro com as narrativas, não buscamos padrões, mas a complexidade das experiências. Miramos uma dialogia com "múltiplos não fundidos" (p. 19), na crença de que os percursos de escolarização, integrados à dinâmica da vida dos estudantes, podem mostrar que as vidas "são pródigas, produzindo não apenas realizações diversas, mas também potenciais não realizados ou parcialmente realizados" (p. 21). Nesse processo, se não negamos a possibilidade de acontecimentos que mudam o curso da vida, junto com eles indagamos a possibilidade de outros acontecimentos, não apercebidos pela nossa própria familiaridade e negligenciados por não adquirir destaque. A vida é vivida nos momentos diários, numa atividade constante em que de minúsculas 
alterações podem decorrer importantes consequências (p. 4-42). No reconhecimento da "rica textura da vida", trabalhamos com uma visão de mundo em que a não finalizabilidade nos mostra um lugar aberto, revelador de nossa responsabilidade no encontro com o outro (p. 55), que só tem significado num conjunto complexo de elementos enraizados na realidade histórica e inseparável da ideia de valor (Tezza, 2003, p. 182-184).

Nessa perspectiva, no cruzamento entre os esforços pessoais e as oportunidades sociais, a ideia de "rumo à universidade" só foi assim formada a partir de uma (re)leitura das trajetórias constituidoras do grupo. Os memoriais apontam mais para uma impossibilidade do que propriamente para uma lógica de experiências escolares que encaminham à universidade. É preciso um olhar sensível para captar, para além das adversidades, as frestas impulsionadoras do curso da escolarização que vão sendo abertas no movimento dos sujeitos. Os estudos do processo de transmissão cultural propostos por Lahire $(1997,2002,2006)$ apontam a complexa rede de determinantes para o sucesso escolar dos segmentos populares. No emaranhado de vivências dos grupos populares, destacamos o valor da escola como elemento de significação para mobilização do grupo pesquisado, construído com experiências mais vinculadas à escola pública. É na crença de que esse espaço pode contribuir para a ascensão social e desenvolvimento pessoal que temos mobilização para o avanço na escolarização, uma crença muitas vezes concebida no grupo como um movimento difuso, uma ideia de que é bom ou importante ir para a escola.

O pressuposto, delineado por Charlot (2000, 2001, 2005, 2006), de que os sujeitos vão produzindo coletivamente uma relação com os saberes escolares realça a aproximação aos estudantes na abordagem do sucesso escolar. Distanciando-se da análise das carências, o autor defende a observação do que acontece com os estudantes considerando o que vivenciam e suas relações com o mundo, com os outros e consigo mesmos. Assim, o conhecimento das lógicas para o estabelecimento de sentidos para os eventos é integrado ao desafio das escolas de criar, para todos os estudantes, condições mobilizadoras para a aprendizagem desses saberes. Nas trilhas da vida, os dados da pesquisa indicam que esse valor da escola defronta-se com as necessidades imediatas; nesse confronto, o trabalho se apresenta como um imperativo para muitos dos integrantes do grupo. Tendo a dificuldade financeira como elo entre as trajetórias, muitas vezes a escolarização é descontinuada em função da demanda do trabalho ou se associa a ele, requerendo novos processos de mobilização para o retorno ou a permanência na escola:

[...] cresci numa filosofia de vida onde a prioridade era o trabalho, mal atingíamos a idade de 13 anos, íamos trabalhar fora e assim ajudar nas despesas da casa. Tudo era com muita dificuldade, estudar passa a ser segundo plano na vida [...]. (M-1)

[...] foi uma infância muito sofrida, desprovida de recursos [...]. Com 9 anos comecei a trabalhar em casa de família [...] até o ano passado não tinha terminado o segundo grau, comecei por diversas vezes e por causa financeira tive que parar [...]. (M-2) 
No reconhecimento das dificuldades, analisam esse contexto com novas apropriações na dialogia reflexiva e problematizadora:

Tratando da questão da permanência na escola, nem todos os integrantes puderam, diante das situações financeiras, participar desse processo regularmente. Utilizando-se das concepções de Cecílio (2004), acreditamos que está embutida em nossa sociedade, devido a anos de construção, a ideia de que o trabalho, independentemente da faixa etária, enobrece o sujeito. Ele afirma ainda que a criança passa a ter significância nos lares de famílias pobres no Brasil quando elas produzem algum tipo de renda, trabalham, e perdê-las seria como desfalcar ou, na pior compreensão, ter prejuízo. (Soares et al., 2011, p. 3).

Diante das agruras do trabalho, podemos também considerar, no diálogo com a valorização da escola, que ela se apresenta como um espaço de fazer coisas não tão penosas, e, com isso, torna-se um lugar melhor de estar.

[...] lembro-me de algumas coisas: o apreço pelas professoras, as brincadeiras na casinha do parquinho, o interesse nos convites de formatura e em participar das danças e festejos escolares, sem contar a paixão por tintas, lápis de cor e atividades de colagem. (M-3)

As privações - de bem-estar, direitos, liberdade, esperança e outras remetem a situá-los como excluídos, uma vez que essas condições iniciais provavelmente derivaram em outras impossibilidades de conquistas na busca de seus direitos, tais como melhores oportunidades de emprego e de participação social (Martins, 1997, p. 18). No entanto, se reconhecemos as implicações dessas dificuldades, também reconhecemos nas ações empreendidas o movimento dos sujeitos na busca por melhores dias, na esperança de que uma vida melhor possa ser conquistada.

Trazendo Drummond para essa dialogia, se apareceram pedras no meio do caminho - e umas ainda persistem, algumas se avizinham, outras se anunciam na perspectiva de futuro... - , elas forçaram saltos, recuos, alteração de rotas e outras dinâmicas, mobilizando também aventuras, aprendizagens e parcerias no percurso. Nas distintas trilhas, mesmo com os empecilhos, a esperança marca a análise das trajetórias, num movimento de significação associado aos apoiadores da jornada: pais, familiares, companheiros, profissionais e amigos, mesmo que muitos tenham ficado pelo caminho na sua própria escolarização.

Se o espaço mais próximo ligado às dinâmicas familiares pode ser remetido a um papel de algoz, por originar abandonos e/ou demandar a participação ativa na mobilização das condições de sobrevivência da família, é importante problematizar as desigualdades sociais que têm forçado famílias a abdicar do projeto de futuro pelas mãos dos filhos:

De família com histórico de perdas e danos, em se tratando de questões financeiras e também em questões emocionais, vivendo conflitos de separação de pais, melhor dizendo, "abandono" de pai [...]. (M-1) 
Até a oitava série, permaneci nesta cidade, trabalhando cada vez mais [...], às vezes não sobrava tempo nem para dormir [...]. O Conselho Tutelar batia na minha casa porque me via trabalhando, mas eu e meus pais sabíamos que era preciso [...]. Eles iam conferir minhas notas no colégio e viam que eram as melhores, então deixavam quieto. (M-4)

A despeito das precariedades, o universo de proximidade é apresentado como um interlocutor significativo da mobilização de forças para a continuidade do percurso:

Meus pais sempre incentivaram e apoiaram meu esforço durante minha jornada nas escolas onde estudei, dizendo que queriam que eu fosse "alguém na vida", o que não é muito diferente do desejo de pais pertencentes às classes populares neste país. (M-5)

[...] meu querido companheiro que sempre acreditou em mim, mais do que eu mesma, foi ele que insistiu por tantas vezes que eu tentasse o vestibular mesmo com todo meu pessimismo e resistência [...]. (M-6)

Esse contexto acena para a complexidade dos processos interativos que sustentam o fluxo da escolarização (Lahire, 1997) e, também, para a interface de projetos nas parcerias para a continuidade da vida (Charlot, 2000), tendo como horizonte uma temporalidade que não se constitui com a reiteração da mesma vida, mas um futuro em que é sempre possível e necessário transformar formalmente essa vida (Bakhtin, 1992, p. 132-136).

[...] é muito comum que pais pertencentes a classes populares valorizem a formação escolar, pelo menos foi assim com a maioria de nós, pois, mesmo passando por privações, não desistiram de ver em nós a mudança de vida possível por meio dos estudos, já que, além de razões financeiras, há também outras muito mais simbólicas ou subjetivas: reconhecimento social ou, ainda, a realização de um sonho pessoal.

Possivelmente, foi por isso que nos empenhamos tanto para chegar até o momento atual: estudamos na Ufes! Sabíamos que, com o esforço, poderíamos alcançar nossos objetivos. (Soares et al., 2011, p. 4).

Na abertura da vida, elos se produzem, podem ser rompidos, novos elos podem ir se estabelecendo, numa busca constante que integra os universos mais próximos a outros contextos:

[...] minha mãe biológica [...] não teve condições de me criar, então me deu para uma senhora. Pouco tempo depois essa senhora [...] não teve mais condições [...] comecei a trabalhar [...] a troco de comida. [...] aos 16 quase 17 anos me casei, pude então constituir a minha família [...]. (M-2)

Nessa interface de contextos, temos processos de mobilização e parcerias associados especialmente aos esforços pessoais na continuidade do percurso, que agregam avaliações e julgamentos inerentes aos processos interativos.

Ao iniciar o ensino médio, esse sonho (o de entrar numa faculdade) foi se transformando em medo, afinal de contas as pessoas são unânimes quando dizem que o ensino da escola pública é péssimo, sem qualidade e até uma perda de tempo. (M-7) 
Os sentidos caracterizadores dos processos de pertencimento, aqui focalizando as trajetórias de escolarização, são produzidos no fazer dos homens, envolvendo tanto as instituições quanto os atores sociais, porque, "[...] na realidade, não são palavras que pronunciamos ou escutamos, mas verdades ou mentiras, coisas boas ou más, importantes ou triviais, agradáveis ou desagradáveis, etc. [...]". Nessa compreensão, reagimos às palavras "que despertam em nós ressonâncias ideológicas ou concernentes à vida" (Bakhtin, Volochínov, 1997, p. 95).

$\mathrm{Na}$ multiplicidade de interlocuções no processo contínuo de estabelecimento de sentidos, as avaliações e julgamentos puderam sofrer novas elaborações, permitindo um repensar constante de si, dos outros, do mundo e, especialmente, do modo de dizer o mundo e se dizer nele (Lima, 2005, p. 28). Nas buscas empreendidas, apresentam-se os projetos de apoio à escolarização, tanto aqueles que propiciam recuperar uma "impossibilidade de estudar quando crianças" quanto os que mobilizam apoio para a inserção na universidade:

Após o divórcio, retornando para Vitória, alimentei um sonho de criança, que foi o de ir para uma faculdade. Não havia terminado o ensino médio, então comecei a fazer provas de banca no EJA. Tive muitas dificuldades com a Matemática, fiz várias provas e não conseguia passar. Mesmo assim, consegui entrar no curso de Letras, faculdade particular, mas não fui além do segundo período. Isso aconteceu em 2005. (M-2)

No meu último ano minha mãe e eu estávamos tentando achar uma forma de pagar um pré-vestibular e não conseguíamos, foi aí que chegou lá na escola uma carta pra mim que dizia que eu havia ganhado um cursinho pré-vestibular de graça pela Sedu. Eu me inscrevi e comecei. Ganhei todo o material e comecei a estudar muito, e, no início de 2009, uma grande surpresa: eu fui aprovada no curso de História, que, pra mim, sempre foi um sonho. (M-8)

Resolvi tentar a seleção do Projeto Universidade Para Todos (PUPT), pois é um projeto onde só pagaria a passagem de ônibus e duas apostilas - o que, sinceramente, naquele momento era muito para mim. (M-7)

[...] fiz EJA à noite e também PUPT à tarde [...] aí consegui passar na Ufes [...]. (M-2)

Assim, na multiplicidade da vida, o ingresso na universidade se apresenta como uma conquista "a duras penas" que coloca em relevo os esforços pessoais:

Então o tão esperado dia do resultado da Ufes saiu. Após o horário de meio dia, estava no meu trabalho numa ótica e recebi um telefonema: era meu namorado, que acabava de me ligar fingindo não saber de nada, pedindo para que eu olhasse o resultado na internet com ele na linha, que ele também queria saber, fingindo ainda não ter olhado. Eu já estava abrindo a página da Ufes, mas falei para ele que não iria olhar, mas não teve como esconder: fui, tomei coragem e comecei a procurar pelo meu nome [..] e, com muito alívio, olhei, olhei novamente e vi na lista dos aprovados da Ufes [cita o próprio nome]. Fiquei muito extasiada e não pude esconder tal alegria de uma grande conquista. Comecei a chorar de emoção, e todos os clientes presentes na ótica começaram a vibrar comigo. (M-6) 
Esse reconhecimento do esforço pessoal se associa à ideia de uma conquista relacionada a apoio na trajetória, em especial dos parceiros de jornada e dos projetos institucionais. Em consequência, uma conquista partilhada, implicando um sucesso também endereçado aos outros:

A confirmação de que uma das muitas vagas deste grande universo pertencia a nós trouxe muita alegria, choro e emoção. A notícia foi recebida com muita empolgação, compartilhada com nossa família, nossos(as) amigos(as), companheiros e filhos(as). [...] a Universidade veio para nós como uma oportunidade de crescimento, muitas foram as primeiras da família a conseguir uma vaga na Universidade. (Soares et al., 2011, p. 6).

Uma conquista que, de partida, já apresenta novos desafios, novas pedras no caminho a mobilizar outros saltos. Além das aprendizagens de inserção no espaço, temos demandas que requerem novas bases para lidar com as circunstâncias:

Passei muitas dificuldades [com a necessidade de mudança de cidade para frequentar a universidade] quanto a dinheiro e moradia. Fiquei um mês na casa de uma prima quarta de meu pai e depois arrumei um emprego de doméstica para morar no emprego e trabalhar. Ganhava $\mathrm{R} \$ 200,00$ por mês. (M-4)

[...]. Apesar de a universidade federal ser pública, o aluno de classe popular encontra uma série de gastos com passagens, alimentação e transporte, tendo que trabalhar para se manter aqui, o que atrapalha o tempo de dedicação aos estudos. (Soares et al., 2011, p. 9).

Adentrar a universidade demanda novas apropriações desse território (Coulon, 2008). Conhecemos as expectativas, os medos iniciais, as experiências desastrosas e engraçadas e como foram se encontrando nesse novo lugar. Também foram mobilizando novos diálogos com a comunidade de origem e com os projetos em que foram se integrando. Nos endereçamentos, a reflexão de que "já não somos os mesmos e não esperamos viver como nossos pais", a partir do percurso, acena o investimento na possibilidade de "uma nova história" (Soares et al., 2011, p. 7), que aponta para a extensão do direito de estar na universidade para um público mais ampliado:

Até hoje nos sentimos responsáveis por honrar nosso nome, nossa escolha e batalhar por nossas metas, buscando sempre incentivar quem quer que seja a lutar por uma vaga no ensino superior [...]. Hoje, estudantes da Ufes, percebemos o quanto é importante o ingresso no ensino superior. Entendemos que essa formação passa por além do âmbito profissional, nos estimula a buscar pelo bem estar do outro, a nos importarmos com o modo de vida da comunidade em geral, trabalhando nossa consciência crítica, propiciando experiências novas e muitos momentos prazerosos [...]. (Soares et al., 2011, p. 8).

Destacamos que, com os percursos apresentados, os jovens de origem popular "vivem mais amargamente a condição juvenil e se encontram em situação de maior vulnerabilidade social" (Scheinvar, Cordeiro, 
2007, p. 56). Nesse quadro, integram a dinâmica ativa na inserção social, visibilizando suas demandas e desejos, que convidam à (re)discussão das "oportunidades escolares" (Dubet, 2003, 2006, 2008) na teia negociativa da produção social da realidade.

Considerando que cada um constrói sua trajetória de um modo particular, vivendo várias experiências que integram diferentes universos que constituem a totalidade da vida, a configuração das trajetórias dos estudantes até a chegada à universidade indica os desafios que emergem para o avanço da escolarização, desafios que não são eliminados com o ingresso na universidade, apontando a necessidade de investimentos institucionais para a continuidade do percurso. Com isso, programas de apoio são necessários e se mostram atrativos para os estudantes.

\section{Nas experiências de início da vida universitária, o encontro com o PET: Conexões/Projeto Educação}

Na pesquisa educacional, o ingresso e a permanência no ensino universitário constituem um campo fecundo de produção de estudos. O cenário brasileiro vem agregando novas nuanças à vida universitária, associadas à ampliação dos anos de escolarização e à expansão da oferta de vagas, mobilizando a focalização da dialogia desse cenário com estudantes das camadas populares, bem como a implementação de programas de apoio a esse segmento. Piotto (2010, p. 2) aponta o seguinte itinerário de produção de pesquisas nesse foco:

\footnotetext{
Pesquisas sobre a adoção de políticas de ações afirmativas no ensino superior no Brasil são relativamente recentes. Debates [em temáticas vinculadas] têm se intensificado a partir do ano de 2002 [...], como atestam, por exemplo, os trabalhos de Moehlecke (2002, 2004), Tragtenberg et al. (2006), Bittar e Almeida (2006), Guarnieri e MeloSilva (2007). Já pesquisas sobre o acesso e a permanência de estudantes das camadas populares no ensino superior começam a surgir, no Brasil, a partir da década de 1990. Trabalhos como os de Portes (1993, 2001), Viana (1998) e Silva (1999) [...] permitem compreender condições que possibilitam trajetórias escolares prolongadas nas camadas populares. Mais recentemente [...], outras pesquisas, como as de Barbosa (2004), Almeida (2006), Zago (2006), Souza (2009a), Souza (2009b), continuam a se debruçar sobre a presença de estudantes pobres em universidades públicas.
}

No campo de produção, os referenciais propostos por Coulon (2008, p. 21) articulam a discussão da democratização do acesso ao ensino superior com a necessária democratização do acesso ao saber, em face dos desafios que se apresentam ao ingressante na vida universitária para "desenvolver um novo habitus escolar" requerido por esse espaço. Nesse processo, o autor propõe três tempos distintos na vivência dos estudantes: do estranhamento, da aprendizagem e da afiliação. O tempo do estranhamento refere-se ao momento inicial de insegurança e desestabilidade das primeiras semanas; o tempo de aprendizagem está associado à adaptação 
ao novo contexto, no primeiro ano do curso, considerando as demandas que se descortinam para o estudante; o tempo de afiliação, finalmente, é o do domínio das exigências requeridas.

Na pesquisa, estamos trabalhando com dados de estudantes que, em sua maioria, estão no primeiro ano do curso, vivenciando, pois, a demanda de apropriação desse espaço em meio a outras necessidades do conjunto da vida. A continuidade do trabalho permitirá avançar na compreensão das dinâmicas de apropriação desse espaço. Nesse contexto, o ingresso dos jovens de origem popular participantes do Programa na universidade é marcado pela busca de incentivos financeiros que possibilitem sua permanência em associação a uma inserção progressiva na cultura acadêmica, com suas demandas e desafios.

Os dados indicam que as ações empreendidas até então pelos estudantes para a garantia das condições materiais de sua existência já não se mostram eficazes, uma vez que muitos empregos não permitem um equacionamento com as demandas e rotinas dos estudos universitários. Para evitar a desistência, os estudantes são instigados a procurar novas opções, podendo chegar aos projetos de apoio presentes na universidade. Assim, acessar o edital, preencher os formulários e encaminhá-los aos setores competentes consiste num primeiro movimento de aprendizagem que se deu no encontro com outro processo de aprendizagem na cultura institucional: o diálogo entre o PET e o PET Conexões que ora se iniciava, trazendo uma experiência prévia do Programa Conexões de Saberes, que, segundo o informe de divulgação,

[...] oferece a jovens universitários de origem popular a possibilidade de adquirir e produzir conhecimentos científicos e, a partir disso, intervir em seu território de origem. Além disso, o programa possibilita o monitoramento e a avaliação, pelos próprios estudantes, do impacto das políticas públicas desenvolvidas em espaços populares. Os participantes do programa recebem apoio financeiro e metodológico. (Disponível em $<$ http://portal.mec.gov.br/index.php?option $=$ com_content\&view $=$ artic le\&id=290\&Itemid $=816>$ )

Assim, novas aprendizagens se efetivam numa teia de negociação e conhecimentos mútuos:

Na assembleia estavam sendo votados vários itens. Alguns tópicos geraram muita polêmica, como o assunto "Novos PETs", pois indagaram que, apesar de estarmos chegando agora, deveríamos ser tratados igualmente. (DC-2 - 24/02/11)

Nessas novas apropriações, os estudantes chegavam a um cenário que sofria transformações, requerendo algumas adaptações no trabalho:

Em nossa primeira socialização enquanto grupo, recebemos de todos ali presentes muita compreensão no sentido de buscarmos juntos a ponta da linha por detrás do emaranhado que iríamos nos envolver [...]. Por se tratar de uma nova ideia, o PET Conexões também conta com plataformas, como dito, recém-criadas que vão sendo modificadas na medida em que aparecem as dificuldades, tornando a utilização muito 
mais elaborada e paciente. Neste contexto também lidamos com a ansiedade em conhecer [...]. (Alves et al., 2011, p. 11).

Nesse momento inaugural do Projeto Educação, temos, então, um movimento de aprendizagem que integra tanto a instituição quanto os alunos na necessidade de conhecer, gerando algumas instabilidades, visto que as respostas até então construídas passam a gerar novas perguntas:

Para mim foi tudo muito confuso: a formalidade, as apresentações de trabalho que não sabia nem o porquê estavam sendo apresentadas para nós. No dia seguinte, fiquei mais perdida ainda - são muitas apresentações, datas, relatórios, reuniões... me senti em outro mundo. E pensei até que não iria me acostumar e que alguém logo iria me desvincular por falta de entendimento. (DC-4 - 28/02/11)

Nesse contexto, novos encontros se efetivam e novos espaços se mostram aos estudantes:

[Na reunião sobre a feira de cursos] a princípio me deparei com uma enorme sala, repleta de quadros em honra a homens que de alguma forma contribuíram para a construção e permanência da universidade. Ainda não havia tido a oportunidade de participar de uma reunião tão formal e em local tão prestigiado [sala da reitoria]. (DC-9 - 14/03/11)

Fui a duas reuniões no Interpet. Foram discutidos alguns assuntos importantes, como, por exemplo, o acontecimento PET. Saí da reunião um pouco desapontada, pois ainda não me sentia adaptada ao grupo, mas acredito que isto é questão de tempo. (DC-6 - 14/03/11)

Não podemos desconsiderar que o movimento dos alunos em direção ao Programa se efetiva mobilizado substancialmente pelas necessidades anunciadas simultaneamente à "alegria da aprovação no vestibular".

[...] a ideia de recebermos, financeiramente falando, por nossa formação foi muito bem aceita. Aliás, esta é uma contribuição importantíssima para a nossa sobrevivência acadêmica [...]. (Alves et al., 2011, p. 11).

Quando cheguei à primeira reunião coletiva, logo minha mente fora tomada por inquietações. Quando de fato começaríamos? Afinal queria o ingresso o mais rápido possível, pois, além de querer o envolvimento com os trabalhos, precisava de dinheiro para sanar minhas despesas acumuladas. (DC-9 - 16/02/11)

Tivemos um encontro coletivo. Estávamos discutindo sobre como poderíamos começar a trabalhar. A tensão nos invadiu, pois todos estavam no aguardo da liberação das bolsas. (DC-2 - 16/02/11)

Destacamos, em meio às aprendizagens oportunizadas no fazer coletivo, o imperativo desse estímulo financeiro e a importância de associá-lo a outros mecanismos de apoio, uma vez que as demandas próprias de alunos de origem popular agregam diferentes necessidades. No grupo recém-criado, já tivemos um "autodesligamento" em função de adversidades que determinaram um retorno ao mercado de trabalho e, consequentemente, o trancamento da matrícula. Também observamos 
o movimento dos integrantes para, cumprindo as ações do projeto e as demandas dos estudos, executarem outros afazeres que agreguem algum ganho financeiro.

Aqui a docência se mostra como um espaço de possibilidades, porque, mesmo no início do curso, permite a atuação em projetos esporádicos de instituições comunitárias, em atividades de apoio a eventos escolares, em pequenas substituições, etc. Se podemos aventar que esse movimento rouba o tempo do processo de escolarização, ele também agrega conhecimentos ao processo formativo. O grupo vai se aproximando do mundo do trabalho na área de formação, acumulando a inserção em lugares diferenciados que dialogam com o curso que frequentam e com as atividades do projeto, em especial com as atividades de extensão que se voltam para o contexto das instituições educativas.

Observamos que a condição de necessidade fortalece uma adesão ao Projeto, marcando a discursividade com a afirmação da importância da proposta:

[...] estamos começando a integrar um programa fantástico, pois tem colocado em voga o espírito pesquisador que temos em nós, explorando nosso trabalho de equipe e aprendendo sempre mais, compartilhando nossas experiências. (Soares et al., 2011, p. 9).

[...] o Encontro como PET Conexistas teve uma representação muito importante em nossas vidas, pois a proposta PET é encantadora à formação acadêmica [...]. (Alves et al., 2011, p. 11).

Para mim, tudo isso se resume em uma nova oportunidade de continuar me formando como uma profissional cidadã, absorvendo todas as experiências que o projeto puder me proporcionar. (M-8)

Cabe lembrar que os endereçamentos da discursividade (encontro com outros grupos iniciantes, integração com grupos mais experientes, informes junto à coordenação dos grupos, reuniões com tutores, etc.) também favorecem um primeiro posicionamento de maior adesão em função dessa vinculação institucional. Nas interações, o discurso de valorização do projeto não pode ser desvinculado da delimitação da presença do outro, de modo a aventar também um discurso reivindicatório de condições de aprendizados que possibilitem a permanência nesse espaço acadêmico, mantendo viva a visibilidade de suas demandas nos destaques das oportunidades buscadas. Esse jogo demonstra que os discursos se constroem sobre discursos, num jogo polifônico entrelaçado aos lugares sociais.

Nas réplicas possíveis, essa afirmação inicial da proposta passa a agregar elementos mais consistentes para o conhecimento do trabalho delineado:

Através do PET (Programa de Educação Tutorial), para o qual fui selecionada, imagino poder potencializar o tripé da universidade, além de fortalecer os campos da educação infantil, da diversidade e de meu desenvolvimento acadêmico e de outros profissionais, reconhecendo sempre os saberes e as ações presentes nos contextos populares. (DC-3 - 15/03/11) 
O conhecimento progressivo das ações do projeto vai fortalecendo a compreensão dos critérios postos para a configuração do grupo, voltado para os estudantes de origem popular. Se a observação desses critérios inicialmente se restringe ao atendimento de um perfil pessoal, posteriormente é possível observar o estabelecimento de aproximações entre esse perfil e o coletivo do grupo:

O convite à participação no PET Conexões no Projeto Educação [enviado após resultado do processo seletivo] foi recebido por todas nós com grande euforia. São várias as razões que nos levaram a este sentimento; apesar de sermos, até o período de inserção ao projeto, desconhecidas, encontramos em nós uma proximidade muito grande, sentimentos de igualdade e de objetivos. (Alves et al., 2011, p. 1).

Uma aproximação também mobilizada nas atividades em função do propósito de reconhecimento dos percursos e de mobilização do fortalecimento do grupo, de modo que, cada vez mais, seus integrantes possam se apropriar do projeto numa autoria coletiva, é assim expressa:

Foi um momento único: pude conhecer melhor meu grupo de trabalho, suas lutas, alegrias, frustrações e a familiaridade de cada história. Não poderia deixar de mencionar as muitas lágrimas que rolaram ao redor daquela mesa... incontáveis. (DC-9 - 02/03/11)

Com as aproximações, as instabilidades e inseguranças são aplainadas e, com isso, vão ganhando destaque o investimento no trabalho e o reconhecimento das parcerias:

[...] aproximação se deu de forma bem harmônica, nos permitindo maior interação com a tutora e entre nós mesmos. Afinal de contas, todas nós estávamos desvelando as coisas e nos constituindo como coautoras do projeto. (Alves et al., 2011, p. 2).

Hoje iniciamos mais uma etapa de nossos trabalhos. Foi uma reunião muito tranquila. Adorei! Motivou-me a estar engajada no PET. (DC-3 $-01 / 03 / 11)$

Gostei do jeito como nos articulamos e percebi que a maioria dos integrantes está se envolvendo bastante. Li alguns diários de campo e os comparei com meus relatos. Percebi que estamos cada vez mais íntimas e que estamos nos socializando muito bem. (DC-5 - 14/03/11)

Sinto-me mais segura no grupo. Estou conhecendo mais as pessoas, e posso dizer que me encontrei mais neste grupo [...]. Acho que é um grupo que tem tudo para crescer. (DC-7 - 14/03/11)

As aproximações na constituição do grupo permitem avançar, então, para a reflexão sobre a formação:

[...] talvez mais importante, participar do Projeto Educação nos proporciona espaço para discutirmos sobre nossas práticas e formações, uma vez que todas nós estamos de alguma forma ligadas à área. Muito mais que preencher nosso lugar, estamos dando fomento ao tipo de profissionais que queremos ser, qual é o profissional que nossa 
sociedade necessita e qual a realidade que devemos superar para responder aos questionamentos anteriores. (Alves et al., p. 1).

Estudei o projeto enviado pela professora e vi que os alunos têm muitas oportunidades de mostrar suas habilidades, pois haverá as reuniões para podermos discutir nossas ideias. E envolvidas com as outras áreas, também poderemos trocar opiniões. Em suma, achei muito interessante.

(DC-2 - 11/02/11)

Assim, na interface com os investimentos institucionais para a continuidade do percurso, marca-se a mobilização dos sujeitos em face das novas exigências que se apresentam, instigando a construção do pertencimento ao grupo de trabalho, um pertencimento em diálogo com as experiências acumuladas, dirigindo-se progressivamente para os focos do projeto. No espaço universitário, o projeto mobiliza atividades autoformadoras, atividades de formação em parceira com a comunidade e atividades coletivas com os outros grupos PETs, além da inserção em eventos que dialoguem com as temáticas envolvidas nos trabalhos do grupo.

Com a proposta, objetiva-se, numa tríade, fortalecer a aprendizagem dos graduandos, estimular o diálogo desses saberes com as comunidades e contribuir com a universidade na abordagem da formação de professores. As primeiras atividades desenvolvidas vão mostrando os investimentos, as necessidades de apoio e, também, as realizações:

[...] estava ansiosa para apresentar o projeto... Nos organizamos e a apresentação fluiu muito bem! Conseguimos alcançar nossos objetivos. As dúvidas dos ouvintes eram muitas, e bem animadas íamos respondendo e contribuindo para o andamento da apresentação. [A tutora] nos auxiliava quando necessário, e dessa forma conseguimos passar nossa apresentação. (DC-3 - 26/02/11)

[Com os planejamentos] Estou criando bastantes expectativas quanto ao projeto de extensão; não vejo a hora de ir para as escolas. Participar desse grupo foi a melhor coisa que fiz até agora, vai me dar uma boa carga de conhecimento prático e teórico. O que escrevi até agora tenho certeza que não escreveria num semestre inteiro [...]. (DC-4 - 15/03/11)

$\mathrm{Na}$ inserção nas atividades vinculadas ao ensino, à pesquisa e à extensão, em diálogo com o acolhimento dos estudantes, expande-se a dialogia incorporando a possibilidade de novas perspectivas para o futuro:

[...] então me perguntei: Este trabalho que estamos desenvolvendo terá importância para um mestrado? Até que ponto poderemos aproveitar disso tudo que viveremos? [...]. (DC-1 - 04/03/11)

[...] Já fazemos muitos sonhos e planos e cremos que, como foi possível chegar até aqui, esta historia não para aqui. Este projeto vem contribuir em todos os aspectos: disciplina de estudo, conhecimento, companheirismo, dedicação, financeiro, entre diversos. E temos certeza que breve continuaremos essa história... (Alves et al., 2011, p. 6).

O diálogo com a docência no horizonte de atuação profissional toma diferentes configurações, reunindo aqueles que já acalentavam "o sonho 
de ser professora" (M-2), resgatando dos universos infantis uma referência a essa possibilidade:

Quando brincávamos, por volta de meus quatro anos, minha irmã, que já estava na escola, era minha "professora"; o muro de nossa casa feito de madeirite -, nosso quadro; as filhas da vizinha, nossas colegas de classe; nosso café da tarde, a merenda; pedaços de carvão ou restos de gesso de construção, nosso giz, etc. Era assim que funcionava a "nossa escola". (M-7)

A esses que destacam uma proximidade com a docência integram-se os que "não pensavam em trabalhar com educação", num diálogo favorecido pelas experiências prévias de escolarização e pelos processos de inserção nos contextos institucionais de trabalho com a participação no projeto. Esse diálogo também se articula às demandas do curso:

Como pretendo fundamentar meu TCC (Trabalho de Conclusão de Curso) na área de Educação Infantil, tenho certeza de que a prática em pesquisas nesse sentido contribuirá muito. Além disso, esse trabalho extracurricular favorece uma formação de professores mais preparados [...]. (DC-5 - 11/02/11)

Nesse contexto, se determinados cursos ligados à licenciatura mostram-se mais próximos às experiências dos estudantes, evidencia-se a demanda de investir nos processos de formação inicial, numa parceria entre a necessidade de programas de apoio a esses estudantes e o fortalecimento da docência como campo de trabalho, de modo a, no "empoderamento" (Candau, 2005, p. 35) dos estudantes, fortalecer a área de atuação.

No jogo social dos tensionamentos, que reúnem os investimentos institucionais e os investimentos dos alunos, destacamos a "satisfação pela oportunidade", a expectativa de aprendizagem e os investimentos nos processos formativos. A aproximação ao projeto de trabalho efetiva-se de forma progressiva com algumas surpresas no percurso, especialmente quanto à integração do ensino, pesquisa e extensão nas ações do Programa e à vinculação com a educação infantil.

Marca-se uma instabilidade inicial relativa ao gerenciamento do sistema, à inserção no coletivo dos grupos PETs da universidade e à integração ao grupo de trabalho, mobilizando o posicionamento ativo nas demandas, a avaliação de possibilidades e a realização de processos organizativos que situam os sujeitos no início da vida universitária e dos trabalhos do grupo. Com isso, o fazer junto e dirigir-se ao outro balizam esse momento inicial, favorecendo as avaliações ante os desafios e expectativas situados no conjunto das políticas públicas voltados a esse segmento.

\section{Considerações finais}

Na totalidade da vida, mantendo as relações entre os planos macro e microssocial na abordagem das conquistas sociais, indicamos que a 
focalização das trajetórias que culminaram no ingresso na universidade e das experiências marcantes nos momentos iniciais da vida universitária com a inserção no PET não pode ignorar "as questões estruturais da sociedade e as políticas educacionais que ainda não deram conta de garantir a democratização do acesso ao ensino em todos os seus níveis e ao saber escolar" (Zago, 2003, p. 289). Assim, se destacamos o movimento interativo dos sujeitos e as aprendizagens desenvolvidas - que demonstram os mecanismos de "sobrevivência" motivadores da atuação (Souza, 2003) -, também não podemos desconsiderar, na continuidade do projeto, que os investimentos institucionais precisam reconhecer o conjunto de demandas que caracterizam o público do Programa.

Trazer os estudantes com seu conjunto de experiências e demandas implica tomar a ideia de conexões de vidas, vidas que parecem em "desalinho", se tomarmos os modelos de alunos até então imaginados para a universidade. Na potência da diversidade, da possibilidade de se descolar de modelos prévios e se abrir para a experiência do outro, ampliar a rede interlocutora, sem desconsiderar as tensões, implica agregar saberes de diferentes fontes e origens, fomentando novas possibilidades de se comunicar com a comunidade. Consideramos que essa é uma experiência geradora de (trans)formações, tanto nos jovens que estão chegando quanto na instituição que os recebe. Na mediação coletiva, consideramos tanto as singularidades de cada um quanto a mobilização institucional que evidencia o projeto de trabalho. Nesse movimento, sabemos do risco de se pautar numa lógica de já ter experiência no ensino universitário, desqualificando a presença de novas demandas e as possibilidades de experimentações que os estudantes de origem popular trazem para o cotidiano da universidade. Nessa complexidade, muitas coisas vão passar e muitas outras vão afetar os sujeitos e a instituição, estimulando a busca por compreensão e por alternativas de atuação (Coulon, 2008).

Os projetos em desenvolvimento não podem abdicar da análise das formas de investimento que são empreendidas no curso das ações, bem como dos mecanismos interativos efetivados pelos estudantes na inserção à universidade. As políticas públicas não se dissociam dos processos de governabilidade da população, ecoando em indicativos de conformação de modos de ser (jovens, estudantes, participantes de determinados grupos, etc.) constituidores dos padrões que não se descolam da produção dos estigmas e da marginalização. Na problematização do discurso monológico das prescrições (Bakhtin, 1992), enfatizamos a importância do investimento na produção compartilhada dos modos de agir, de modo a marcar a diversidade e o protagonismo dos integrantes no curso das ações (Charlot, 2005).

Finalizamos resgatando a visão profundamente relacional de Bakhtin, associando a polifonia celebratória à heteroglosia na compreensão de que os atos de troca deixam os interlocutores modificados. Reconhecendo a polifonia, destacamos os encontros e as aprendizagens do grupo com a inserção na vida universitária e no Programa, bem como sua contribuição na promoção de novas dinâmicas no contexto da instituição e da comunidade de origem. Remetendo esse movimento à heteroglosia em suas "sugestões de conflito social, enraizado não nas dissonâncias individuais 
aleatórias, mas nas profundas clivagens estruturais da vida social" (Stam, 1993, p. 167), destacamos as tensões inerentes às disputas negociativas dos direitos sociais. No duplo movimento de celebração e de crítica, as conquistas alcançadas com os projetos vinculados às ações afirmativas não podem justificar o arrefecimento da luta por novas conquistas com vista ao reconhecimento da educação como um direito na sua plenitude para todos os estudantes, incluindo os jovens universitários de origem popular.

Com esse referencial, acreditamos que entramos numa cadeia dialógica nas temáticas que tomamos como pauta nas lutas de nosso tempo, isto é, que já há um percurso construído e que passamos a dialogar e contribuir com esse percurso, que acumula experiências indicadoras para a continuidade das ações. Em resumo, a pauta das ações afirmativas tem uma história que pode ser contada e atualizada. Integrando essa cadeia de conversação, no convite às contrapalavras, esperamos que este texto contribua com a manutenção dessa cadeia dialógica, fortalecendo a visibilidade da temática com vista a problematizar as ações, fortalecer espaços de trocas de saberes, suscitar novos estudos e estimular novas iniciativas, no diálogo sem fim da existência humana.

\section{Referências bibliográficas}

ABAD, M. Crítica política das políticas de juventude. In: FREITAS, M. V. de; PAPA, F. de C. (Orgs.). Políticas públicas: juventude em pauta, São Paulo: Cortez, Ação Educativa, Fundação Friedrich Ebert, 2003.

ALVES, K. K. et al. Movimento inicial dos estudantes no Programa de Educação Tutorial: Conexões/Projeto Educação. Vitória: 2011. [Circulação restrita].

BAKHTIN, M. M. Problemas da poética de Dostoiévski. Rio de Janeiro: Forense Universitária, 2005.

- A cultura popular na Idade Média e no Renascimento: o contexto de François Rabelais. São Paulo: Hucitec, 2002.

Questões de literatura e de estética: a teoria do romance.

São Paulo: Hucitec, 1998.

. Toward a Philosophy of the Act. Austin: University of Texas

Press, 1993. (Tradução para uso didático e acadêmico de Carlos Alberto Faraco e Cristóvão Tezza - circulação restrita).

. Estética da criação verbal. São Paulo: Martins Fontes, 1992.

BAKHTIN, M. M.; VOLOCHÍNOV, V. N. Marxismo e filosofia da linguagem. São Paulo: Hucitec, 1997. 
BARBIER, R. L'approche transversal: l'écoute sensible em sciences humaines. Paris: Anthropos, 1996. (Coll. Science Sociale et Exploration Interculturelle).

BOBBIO, N. A era dos direitos. Rio de Janeiro: Elsevier, 2004.

BOGDAN, R. C.; BIKLEN, S. K. Investigação qualitativa em educação: uma introdução à teoria e aos métodos. Porto, Portugal: Porto Ed., 1994.

BOSI, A. Alfredo Bosi decifra enigmas de Machado de Assis (fragmento do livro "O enigma do olhar", São Paulo: Ática, 1999). Revista Brasileira de Literatura CULT, São Paulo, p. 41, abr. 1999.

CANDAU, V. M. Sociedade multicultural e educação: tensões e desafios. In: CANDAU, V. M. et al. Cultura(s) e educação: entre o crítico e o pós-crítico. Rio de Janeiro: DP\&A, 2005. p. 13-37.

CASTEL, R. As transformações da questão social. In: BÓGUS, L. et al. (Orgs.). Desigualdade e a questão social. São Paulo: Educ, 1997.

CHARLOT, B. Jovens de Sergipe: como são eles, como vivem, o que pensam. Aracaju: Governo de Sergipe, 2006. [Relatório de pesquisa].

- Relações com o saber, formação dos professores e

globalização: questões para a educação. Porto Alegre: Artmed, 2005.

. Os jovens e o saber: perspectivas mundiais. Porto Alegre:

Artmed, 2001.

. Da relação com o saber: elementos para uma teoria. Porto

Alegre: Artmed, 2000.

COULON, A. A condição de estudante: a entrada na vida universitária.

Salvador: Edufba, 2008.

DAGNINO, E. Os movimentos sociais e a emergência de uma nova noção de cidadania. In: (Org.). Anos 90: política e sociedade no Brasil. São Paulo: Brasiliense, 1994.

DUBET, F. Que é uma escola justa? São Paulo: Cortez, 2008.

Sobre a violência e os jovens. Cadernos de Ciências Humanas, v. 9, n. 15, p. 11-31, jan./jun. 2006. Disponível em <www.unesc.br/ revistas $>$. Acesso em 20/08/2010.

. Desigualdades multiplicadas. Ijuí: Ed. Unijuí, 2003. 
FONTANA, R. A. C. A elaboração conceitual: a dinâmica das interlocuções na sala de aula. In: SMOLKA, A. L.; GÓES, C. de (Orgs.). A linguagem e o outro no espaço escolar: Vygotsky e a construção. 2. ed. Campinas: Papirus, 1993.

FREIRE, P. Novos tempos, velhos problemas. In. SERBINO, R. V. et al. (Orgs). Formação de professores. São Paulo: Unesp, 1998. p. 41-47.

FREITAS, M. V.; PAPA, F. de C. Políticas públicas: juventude em pauta. São Paulo: Cortez, 2003.

KONDER, L. A questão da ideologia. São Paulo: Companhia das Letras, 2002.

LAHIRE, B. A cultura dos indivíduos: Porto Alegre: Artmed, 2006. 2002 . O homem plural: os determinantes da ação. Petrópolis: Vozes, Sucesso escolar nos meios populares: as razões do improvável. São Paulo: Ática, 1997.

LIMA, M. E. C. de C. Sentidos do trabalho: a educação continuada de professores. Belo Horizonte: Autêntica, 2005.

MARTINS, José de Souza. Exclusão social e a nova desigualdade. São Paulo: Paulus, 1997.

MÉSZÁROS, I. A educação para além do capital. São Paulo: Boitempo, 2005.

MORSON, G. S.; EMERSON. C. Mikhail Bakhtin: criação de uma prosaística. São Paulo: Edusp, 2008.

PAIS, José Machado. A construção sociológica da juventude: alguns contributos. Análise Social, Lisboa, v. 25, n. 105/106, p. 139-165, 1990.

PIOTTO, Débora. C. Subjetividade e ações afirmativas: experiência universitária de egressos de escolas públicas na USP. Trabalho apresentado na 33 $3^{\mathrm{a}}$ Reunião Anual da Associação Nacional de Pós-graduação e Pesquisa em Educação (ANPEd), Caxambu, 2010. Disponível em < http://www.anped.org.br/33encontro/internas/ver/ trabalhos-gt14>. Acesso em 10 fev. 2011.

RUA, M. das G. As políticas públicas e a juventude dos anos 90. In: . Jovens acontecendo na trilha das políticas públicas. Brasília: CNPD, 1998. 2 v. p. 731-752. 
SCHEINVAR, E.; CORDEIRO, D. Juventude em "risco social"? Dilemas e perspectivas por entre as pedras das políticas públicas dirigidas aos jovens. Informativo Técnico-Científico Espaço Ines, Rio de Janeiro, n. 27, p. 55-63, jan./jul. 2007.

SOARES L. C. et al. As trajetórias que constituem o grupo PET Conexões: Educação na Universidade Federal do Espírito Santo. Vitória: Ufes, 2011. [Circulação restrita].

SOUZA, M. I. P. de. Fronteiras do cotidiano. In: GARCIA, R. L. (Org.). Método: pesquisa com o cotidiano. Rio de Janeiro: DP\&A, 2003. p. 245-262.

SPOSITO, M. P. (Coord). Estado do conhecimento: juventude e escolarização. 2000a. Disponível em < http://www.aracati.org.br/portal/ pdfs/13_Biblioteca/Publicacoes/juventude_escolarizacao.pdf $>$. Acesso em: 30 out. 2010.

Algumas hipóteses sobre as relações entre os movimentos sociais, juventude e educação. Revista Brasileira de Educação, Rio de Janeiro, n. 13, p. 73-94, jan./abr. 2000b. Disponível em: < http://www. anped.org.br/rbe/rbedigital/RBDE13/RBDE13_06_MARILIA_PONTES_ SPOSITO.pdf>. Acesso em: 30 out. 2010.

SPOSITO, M. P.; CERRANO, P. C. R. Juventude e políticas públicas no Brasil. Revista Brasileira de Educação, Rio de Janeiro, n. 24, p. 16-39, set./dez. 2003. Disponível em <http://www.anped.org.br/rbe/rbedigital/ RBDE24/RBDE24_05_MARILIA_PONTES_SPOSITO_E_PAULO_CESAR_ RODRIGUES_CAR.pdf>. Acesso em: 30 out. 2010.

STAM, R. Mikhail Bakhtin e a crítica cultural de esquerda. In: KAPLAN, E. A. (Org.). O mal-estar no pós-modernismo: teorias e práticas. Rio de Janeiro: Zahar, 1993.

TEZZA, C. Entre a prosa e a poesia: Bakhtin e o formalismo russo. Rio de Janeiro: Rocco, 2003.

VELHO, G. Observando o familiar. In: . Individualismo e cultura: notas para uma antropologia da sociedade contemporânea. 7. ed. Rio de Janeiro: Zahar, 2004. p. 121-132.

ZAGO, N. A entrevista e seu processo de construção: reflexões com base na experiência prática de pesquisa. In: ZAGO, N.; CARVALHO, M. P.; VILELA, R. A. T. (Orgs.). Itinerários de pesquisa: perspectivas qualitativas em sociologia da educação. Rio de Janeiro: DP\&A, 2003. p. 287-309. 
Valdete Côco, doutora em Educação pela Universidade Federal Fluminense (UFF), é professora no Centro de Educação da Universidade Federal do Espírito Santo (Ufes) e integrante da Linha de Pesquisa Cultura, Currículo e Formação de Educadores, do Programa de Pós-Graduação (PPGE/CE/Ufes).

valdetecoco@hotmail.com

Recebido em 20 de abril de 2011.

Aprovado em 23 de janeiro de 2012. 